\section{'Snowstorm': A White sh2 Hybrid Sweet Corn and its Female Parent UFISH 8029}

\author{
B.T. Scully ${ }^{1}$, R.L. Beiriger ${ }^{2}$, and E.A. Wolf ${ }^{3}$ \\ Everglades Research and Education Center, Institute of Food and Agricultural \\ Sciences, University of Florida, 3200 Old Palm Beach Road, Belle Glade, \\ FL 33430-8003
}

Additional index words. Zea mays, pedigree breeding

The Florida sweet corn (Zea mays L.) industry relies primarily on hybrids with the shrunken2 (sh2) endosperm gene (Mains, 1949) and markets its product almost exclusively for fresh consumption. Most of this crop is shipped throughout the eastern seaboard and the midwestern regions of the United States, while a small portion is exported. In Florida, this industry has been valued at over $\$ 100$ million annually, and has a year-round cropping schedule. Over onethird of this crop is harvested in May and commonly $<5 \%$ in January (Florida Agricultural Statistics Service, 1998). Statewide production fluctuates between 16,000 and 20,000 ha, down from nearly 24,000 ha a decade ago. Florida has four major production regions, but more than half of the crop is grown on the histosols of the Everglades Agricultural Area (EAA), a region adjacent to the southern shore of Lake Okeechobee.

About half a dozen companies market hybrid sweet corn seed in Florida. In a 1999 survey that represented $75 \%$ of the Florida crop (J.B. Long, personal communication), growers indicated that $60 \%$ of the production area would be planted to yellow, $20 \%$ to bicolor, and $20 \%$ to white hybrids. Growers projected a $5 \%$ increase in market demand for bicolor hybrids and a collateral reduction in yellow hybrids; the allocation for white hybrids was expected to remain constant. Presently, growers use $\approx 25$ hybrids of all endosperm colors, but have depended most heavily on only 10 to 12 . Among these predominant hybrids, only three or four white hybrids satisfy the industry needs. The purpose of our breeding effort was to develop a white $s h 2$ hybrid and enlarge the number of

Received for publication 22 June 2000. Accepted for publication 14 Nov. 2000. Florida Agricultural Experiment Station Journal Series No. R-07251. This research was supported by the NE-124 Regional Hatch Project, Illinois Foundation Seed, Florida Foundation Seed, and Crookham Co. The cost of publishing this paper was defrayed in part by the payment of page charges. Under postal regulations, this paper therefore must be hereby marked advertisement solely to indicate this fact.

${ }^{1}$ Associate Professor, Plant Breeding and Genetics. To whom requests for reprints should be addressed.

E-mail address: brts@gnv.ifas.ufl.edu

${ }^{2}$ Biologist.

${ }^{3}$ Professor Emeritus. hybrids available to Florida growers. Additional emphasis was placed on the development of a white inbred that would be conducive to seed production in Idaho.

\section{Orgin}

'Snowstorm' was evaluated as test hybrid UFW 1429R. UFISH 8029 is the seed parent and CRSH2-14, a proprietary inbred of the Crookham Co. of Caldwell, Idaho, the male parent. UFISH 8029 was developed by backcross procedures that used FA56a as the recurrent parent. The inbred FA56a is a selected version of the inbred 'Florida 56' (Wolf, 1975), which was developed as a backcross conversion of the sugaryl (sul) inbred Ia 2256 (Gerdes et al., 1993; Tracy, 1994). In the first backcross sequence, FA56a was crossed with a Crookham white endosperm sul inbred and backcrossed four times to FA56a. FA56a was used interchangebly as either the seed or pollen parent. Selfing to recover the white endosperm genotype was performed after the $\mathrm{BC}_{1}, \mathrm{BC}_{2}$ and the $\mathrm{BC}_{4}$ generations, with the breeding line UF 84-66 selected in the $\mathrm{BC}_{4} \mathrm{~F}_{2}$ generation. In a second parallel backcross scheme, FA56a was used as the recurrent parent up through two backcrosses. This second backcross scheme was intended to introgress the Htn gene (Leonard et al., 1988) into FA56a for resistance to races year environments from 1997-99.

y Data available for 1999 only.
1,2 , and 23 of northern corn leaf blight (NCLB) found in Florida and caused by Exserohilum turcicum (Pass.) Leonard and Suggs. The Htn donor parent was obtained from the Harris-Moran Seed Co. After two backcross and selfing generations, the NCLBresistant line 83RW5-1 was identified. Breeding lines UF84-66 and 83RW5-1 were combined, entered into a pedigree breeding program and selfed through to the $\mathrm{F}_{8}$ generation when CC0 89:8029-2 was identified and entered into test crosses. Prior to a bulk increase in Idaho, an additional two selfing generations of single seed descent were performed in the greenhouse to insure genetic purity and uniformity. The Htn gene was not selected after the $\mathrm{F}_{4}$ generation, but white endosperm and other horticultural traits were selected throughout.

\section{Description}

'Snowstorm'. 'Snowstorm' was tested in five trials from 1997 to 1999 . Spring trials were planted at two sites in 1999 and at a single site in 1998 in the EAA. Two fall trials were planted in 1997 in the Miami-Dade region. For each experiment, a randomized complete-block design was replicated four times. Over 30 common traits (Kaukis and Davis, 1986; Scully et al., 1994) were measured and compared with those of the white hybrid 'SS 8101' and the bicolor hybrid 'SS 8102' from Abbott \& Cobb Seed Co., Feasterville, Pa. 'Snowstorm' and 'SS 8101' are both midseason hybrids that reach roasting stage $5 \mathrm{~d}$ later than 'SS 8102' (Table 1). Tassel and silk production are synchronized in 'Snowstorm', but not in 'SS 8101' and 'SS 8102'.

Agronomically, 'Snowstorm' was generally superior to 'SS 8101' and comparable with 'SS 8102'. It emerged earlier and had better seedling stand counts than either standard, and was significantly earlier than 'SS 8101' (Table 1). As rated on a 1-5 scale, 'Snowstorm' was more vigorous and more uniform than either standard, but only significantly more vigorous than 'SS 8101'.

Table 1. Comparison of plant trait means \pm SD for 'Snowstorm' with those of the standard commercial white hybrid 'SS 8101' and bicolor hybrid 'SS 8102' grown in southern Florida over five site-

\begin{tabular}{|c|c|c|c|}
\hline Ear traits & Snowstorm & SS 8101 & SS 8102 \\
\hline Days to maturity (DTM) & $79.2 \pm 6.5$ & $75.9 \pm 5.9$ & $74.9 \pm 4.5$ \\
\hline Days to mid-tassel (DTT) & $55.0 \pm 4.2$ & $54.4 \pm 3.9$ & $53.1 \pm 3.5$ \\
\hline Days to emergence (DTE) & $5.5 \pm 0.5$ & $6.4 \pm 0.5$ & $5.9 \pm 0.6$ \\
\hline Seedling stand count $(\%)$ & $95.5 \pm 4.3$ & $94.5 \pm 3.2$ & $93.8 \pm 3.8$ \\
\hline Vigor $(1-5 \text { scale })^{\mathbf{z}}$ & $4.1 \pm 0.3$ & $2.6 \pm 0.3$ & $4.1 \pm 0.3$ \\
\hline Seedling uniformity (1-5 scale) & $4.0 \pm 0.5$ & $3.7 \pm 0.5$ & $3.7 \pm 0.6$ \\
\hline Stalk quality $(1-5 \text { scale })^{y}$ & $4.9 \pm 0.3$ & $2.2 \pm 0.3$ & $3.7 \pm 0.5$ \\
\hline Plant height (cm) & $186.8 \pm 27.4$ & $174.2 \pm 28.2$ & $196.1 \pm 11.0$ \\
\hline Top ear height $(\mathrm{cm})$ & $61.1 \pm 15.9$ & $52.4 \pm 13.9$ & $61.0 \pm 9.7$ \\
\hline Tiller number & $8.9 \pm 11.8$ & $10.7 \pm 14.8$ & $18.3 \pm 13.6$ \\
\hline Tiller height & $33.3 \pm 38.6$ & $39.1 \pm 40.2$ & $40.9 \pm 23.3$ \\
\hline Plants with 2nd ear (\%) & $54.0 \pm 28.4$ & $54.8 \pm 24.6$ & $44.2 \pm 28.7$ \\
\hline Husk flag length (cm) & $6.5 \pm 3.1$ & $6.5 \pm 3.2$ & $5.0 \pm 2.3$ \\
\hline Husk extension $(\mathrm{cm})$ & $2.3 \pm 0.8$ & $2.7 \pm 1.2$ & $2.5 \pm 0.5$ \\
\hline Ease of husking (1-5 scale) & $3.2 \pm 1.1$ & $3.0 \pm 0.8$ & $3.4 \pm 0.7$ \\
\hline Shank length $(\mathrm{cm})$ & $3.8 \pm 1.7$ & $5.8 \pm 2.5$ & $5.9 \pm 1.1$ \\
\hline
\end{tabular}

${ }^{\mathrm{z}}$ This 1-5 scale (least to greatest) is subjective and based on visual assessment. 
Stalk quality, also rated on a 1-5 scale, was significantly better for 'Snowstorm' than for the standards, which bowed from $60 \%$ to $100 \%$ while 'Snowstorm' bowed between $0 \%$ and $30 \%$. 'Snowstorm' had fewer and shorter tillers than either standard (Table 1). Tiller number, tiller height, and stalk bowing are commonly used to assess harvest efficiency; field crews generally harvest with less fatigue when corn stalks are more erect and have fewer and shorter tillers.

Plant height, top ear height, and percentage of stalks with a second ear were comparable for these three hybrids. 'Snowstorm' differed significantly from the standard hybrids for husk extension beyond the ear tip and shank length, but not for flag leaf length or husk tightness (Table 1). The husked ears of the three hybrids were similar in dimension and row quality, but 'Snowstorm' was penalized for ear shape and appearance because of lower tip quality as measured by tip blanking, tip extrusion and the length of unfilled tip (Table 2). For the majority, minimum and maximum row count traits, the two standards were lower than 'Snowstorm' (Table 2). 'Snowstorm' had higher row counts, with an ear width equivalent to the standard hybrids, which resulted in visibly smaller and more attractive kernels.

Extrapolated plant populations averaged from 52,000 to 53,000 plants/ha, and given the practice of harvesting one ear per plant, theoretical yields were projected to range between 1038 and 1055 crates $(1$ crate $\approx 1$ bushel $\approx 52$ ears)/ha for each hybrid. Yields averaged 771,862 , and 865 crates/ha for 'Snowstorm', 'SS 8101', and 'SS 8102', respectively. Despite these reduced yields and some undesirable ear traits, 'Snowstorm' has met with widespread grower acceptability in North America and abroad, because of its positive and dependable agronomic qualities. Less bowing and lodging of stalks occur than in the two standards, and the ears are placed higher on shorter plants (Table 1). These traits, coupled with fewer and shorter tillers, also contribute to agronomic quality. Additionally, ears are pulled more easily from the stalk and have shorter shanks, which further contribute to field crew efficiency. Other qualities, including vigor, uniformity and stand have also attracted growers. Despite the poorer tip quality on 'Snowstorm', the increased use of "tray packs" in the marketplace has reduced the importance of this trait, as the tips are cut off prior to packaging. Furthermore, growers have refined field management schemes, including adjustments in crop spacing and foliar nutrition to ameliorate tip problems.

UFISH 8029. After 4 years of testing in Idaho, UFISH 8029 consistently tasseled in $\pm 70 \mathrm{~d}$ and silked in $\pm 73 \mathrm{~d}$. The less consistent male parent, CRSH2-14, tasseled in $69 \mathrm{~d}$, and silked in $72 \mathrm{~d}$. Comparable inbreds, including CRSH2-44, tasseled and silked in $72 \mathrm{~d}$, while FAHT 32b did so in 73 and $75 \mathrm{~d}$, respectively. The early inbred CRSH2-913 tasseled and silked in 59 and $58 \mathrm{~d}$, respectively. For 'Snowstorm' seed production, the male parent is delayed 0 to $5 \mathrm{~d}$ behind UFISH 8029. In Idaho, UFISH 8029 ranged $\leq 200 \mathrm{~cm}$, but typically averaged between 160 and $180 \mathrm{~cm}$ in height. In Florida, plant height was reduced to 140 to $160 \mathrm{~cm}$. The stalk is light to medium green with a basal diameter of 2.4 $\mathrm{cm}$ with two or three brace roots on $\approx 60 \%$ of the plants. Tillers rarely develop on Floridagrown plants, but in Idaho one or two tillers are common, and attain heights nearly $75 \%$ of that of the main stem. The top ear is expressed $\pm 61.0 \mathrm{~cm}$ above the ground with six or seven nodes above the top ear. Top ear height ranges from 50 to $55 \mathrm{~cm}$ in Florida. At 21 d after pollination (DAP) or "roasting" stage, 10 to 12 leaves are visible, with the lower two leaves partly to completely senescent. The length of the top ear internode ranges from 7 to $12 \mathrm{~cm}$, with an average length and width of 10.1 and $1.7 \mathrm{~cm}$, respectively.

UFISH 8029 generally produces two ears per stalk with a maturity difference of $\pm 3 \mathrm{~d}$. With this tendency for second ear production, UFISH 8029 is preferred as a seed parent and often exceeds the target yield of 1000 $\mathrm{kg} \cdot \mathrm{ha}^{-1}$. At maturity, top ears in the husk range in width from 5.2 to $6.5 \mathrm{~cm}$ and average $5.9 \mathrm{~cm}$, and average $4.4 \mathrm{~cm}$ without the husks.
Top and bottom ears average $15.8 \mathrm{~cm}$ in length and range from 14 to $18 \mathrm{~cm}$. In Florida this range and average length is $2 \mathrm{~cm}$ shorter. Kernel rows are distinct, mostly straight on a slightly tapered cob that is occasionally tasselated $\leq 1 \mathrm{~cm}$. Top and second ears usually have 16 and 14 rows, respectively, with a range of 12 to 16 rows for both ears. Ears are held close to the stalk at $\leq 15^{\circ}$ from vertical. At seed maturity ( $\pm 35 \mathrm{DAP})$, ears with tan to buff-colored husks are still held upright.

At roasting stage, light to medium green husks cover the ear reasonably tightly and extend $7.5 \mathrm{~cm}$ beyond the tip. In Idaho, husk flag leaves are long, averaging $18 \mathrm{~cm}$ on the top ear and $21.3 \mathrm{~cm}$ on the second ear, with more variation among the top ear flag leaves. Ears have 15 to 18 husk leaflets that average $23.5 \mathrm{~cm}$ in length, excluding the flag leaf, and are attached to seven or eight shank nodes. Shank length averages $8.4 \mathrm{~cm}$ in Idaho, and $\leq 7.4 \mathrm{~cm}$ in Florida. Fresh silks are light ivory to light pale green and extrude $7.7 \mathrm{~cm}$ on average. Cobs are off-white, round in transect, $0.85 \mathrm{~cm}$ in diameter, light, and easily broken. The seeds of UFISH 8029 typically have the $s h 2$ characteristic with a translucent pericarp, white aleurone, and endosperm. At the midcob region, kernels range in length from 8 to $10 \mathrm{~mm}$, averaging $9 \mathrm{~mm}$, while kernel thickness ranges from 4 to $6 \mathrm{~mm}$ and averages 4.90 $\mathrm{mm}$. Kernels are mostly flat with $\leq 15 \%$ "round" seeds. Depending on sieve size, there are typically 753 to 914 seeds/100 g sample.

Pollen shed from UFISH 8029 is intermediate for a sh2-type inbred. Pollen and anthers are yellow, while glumes are light green. The central spike averages $23.7 \mathrm{~cm}$ in length, ranging from 21 to $28 \mathrm{~cm}$, and 1.46 $\mathrm{cm}$ in width, ranging from 1.1 to $1.8 \mathrm{~cm}$. On average, 17 secondary and four tertiary branches are held between a $45^{\circ}$ and $60^{\circ}$ angle from vertical. In Florida, these counts and dimensions are reduced by $\approx 20 \%$. Secondary branches range from 7.5 to $23.5 \mathrm{~cm}$ in length, and are typically 7 to $11 \mathrm{~mm}$ wide. The peduncle subtending the tassel averages $18.8 \mathrm{~cm}$ from the top node to the tassel base with $3.1 \mathrm{~cm}$ exposed above the top leaf sheath. Measured at the mid-internode, the average width of the bare peduncle is $8 \mathrm{~mm}$.

\section{Availability} white hybrid, 'SS 8101' and the commercial bicolor hybrid 'SS 8102' grown in southern Florida over five site-year environments from 1997-99.

\begin{tabular}{lccr}
\hline \hline Ear traits & Snowstorm & SS 8101 & SS 8102 \\
\hline Ear length (cm) & $18.0 \pm 1.3$ & $18.6 \pm 1.0$ & $19.5 \pm 0.6$ \\
Minimum & $16.7 \pm 1.5$ & $17.4 \pm 1.4$ & $18.2 \pm 1.2$ \\
Maximum & $19.3 \pm 1.4$ & $19.9 \pm 1.3$ & $20.4 \pm 0.4$ \\
Ear width (cm) & $4.7 \pm 2.2$ & $4.7 \pm 1.7$ & $4.7 \pm 1.0$ \\
Tip blanking (\%) & $74.0 \pm 24.6$ & $25.0 \pm 25.0$ & $23.3 \pm 38.0$ \\
Length of unfilled tip (cm) & $2.4 \pm 1.2$ & $0.9 \pm 0.8$ & $0.51 \pm 0.8$ \\
Extruded tips (\%) & $2.4 \pm 3.5$ & $0.7 \pm 1.0$ & $0.1 \pm 0.2$ \\
Row quality (1-5 scale) & $3.6 \pm 0.6$ & $3.7 \pm 0.5$ & $3.7 \pm 0.5$ \\
Ear shape (1-5 scale) & $2.9 \pm 0.7$ & $3.4 \pm 0.6$ & $3.3 \pm 0.9$ \\
Ear appearance (1-5 scale) & $2.7 \pm 0.5$ & $3.1 \pm 0.5$ & $3.3 \pm 0.8$ \\
Majority row count & $16.8 \pm 1.4$ & $15.9 \pm 1.5$ & $16.6 \pm 1.0$ \\
Minimum & $14.4 \pm 1.4$ & $13.9 \pm 1.8$ & $14.2 \pm 1.0$ \\
Maximum & $18.1 \pm 2.0$ & $18.0 \pm 1.6$ & $17.8 \pm 1.0$ \\
\hline
\end{tabular}

${ }^{2}$ This 1-5 scale (least to greatest quality or desirability) is subjective and based on visual assessment. ${ }^{y}$ Maximum, minimum, and majority row counts are based on a random ten-ear sub-sample taken from each experimental unit. The mean \pm SD values estimate the averages from these counts.

\section{'Snowstorm' and the inbred UFISH 8029} are the intellectual property of the Florida Agricultural Experiment Station at the Univ. of Florida. 'Snowstorm' is exclusively licensed to Illinois Foundation Seed, Champaign, as the master licensee. UFISH 8029 is available for research and cooperative hybrid development by contractual arrangement. Interested persons may contact B.T.S. for seed samples.

\section{Literature Cited}

Florida Agricultural Statistics Service. 1998. Florida agricultural statistics: Vegetable summary. p. 20-22. Fla. Agr. Stat. Serv., Fla. Dept. Agr. and Consumer Affairs, Orlando, Fla. 
Gerdes, J.T., C.F. Behr, J.G. Coors, and W.F. Tracy. 1993. Compilation of North American maize breeding germplasm. Crop Sci. Soc. Amer., Madison Wis

Kaukis, K. and D.W. Davis. 1986. Sweet corn breeding, p. 477-512. In: M.J. Basset (ed.). Breeding vegetable crops. AVIPubl., Westport, Conn.

Leonard, K.J., Y. Levy, and D.R. Smith. 1988.
Proposed nomenclature for pathogenic races of Exserohilum turicum on corn. Plant Dis. 73:776-777.

Mains, E.B. 1949. Heritable characters in maize: Linkage of a factor for shrunken endosperm with the $a 1$ factor for aluerone color. J. Hered. 40:21-24.

Scully, B.T., G.S. Nuessly, R.N. Raid, M.L. Gardiner and S.W. Marshall. 1994. Dictionary of traits for fresh market sweet corn production in Florida. Subtrop. Plant Sci. 46:50-61

Tracy, W.F. 1994. Sweet corn, p. 148-181. In: A.R. Hauller (ed.). Specialty corns. CRC Press, Boca Raton, Fla.

Wolf, E.A. 1975. 'Florida 32' and 'Florida 56': Two shrunken-2 $\left(s h_{2}\right)$ sweet corn inbreds. Circ. S-235. Inst. Food and Agr. Sci., Univ. Fla Gainesville. 